\title{
Julio Correa, visto por sí mismo
}

\begin{abstract}
A las diez de la mañana, cuando abogados y procturadores en animaA da tertulia comentan en el café, El Polo Norte, las incidencias de los juicios en que intervienen en el tribunal frontero, un hombre que no es ni abogado ni procurador entra en ese mismo café. Este hombre, pobremente vestido, ni alto ni bajo, tímido y receloso, echa una mirada rápida en torno, se acerca a una mesa apartada, coloca un fajo de papeles sobre una silla $y$, sin sacarse el raído sombrero, se sienta lentamente, cuidando de pasar inadvertido. Este hombre es don Julio Correa, poeta y dramaturgo paraguayo.

El mozo le trae una humeante tacita de café. Don Julio la bebe $y$, entre sorbo y sorbo, echa un vistazo al fajo de papeles que momentos antes ha colocado sobre la silla próxima. Nadie sabe qué son estos papeles. Acaso poemas, o manuscritos de un drama, o fojas de un expediente, o, tal vez, panfletos subversivos. Porque este hombre moreno, mal vestido, de tímidos ojos azules que saben mirar con infantil asombro o torva mirada de enojo, vive misteriosamente. Vive en perpetua lucha. Es un alma incandescente: ama y odia sin medida. Odia a los malos, o a los que cree que son malos, y ama a los humildes. Si no hace mucho tiempo salió a las tablas como autoractor, prefiere ahora vivir en la penumbra, con pocos amigos y muchos enemigos. $\mathrm{Y}$ ya no escribe más. Acaso espere la libertad para escribir.

Mientras tanto, en la ciudad de Asunción, cuyos suburbios ha cantado otrora, se lo ve caminar a lo largo de las calles, recatándose junto a las paredes, no sólo ávido del alivio de sombra que éstas proyectan sobre la acera, sino como ansioso de evadir la pública atención. $\mathrm{Y}$ si viste mal, él lleva sus raídas ropas como una defensa
\end{abstract}


y como un desafío. Porque su timidez mal disimula un fiero orgullo de artista y un desdén sin límites hacia el burgués:

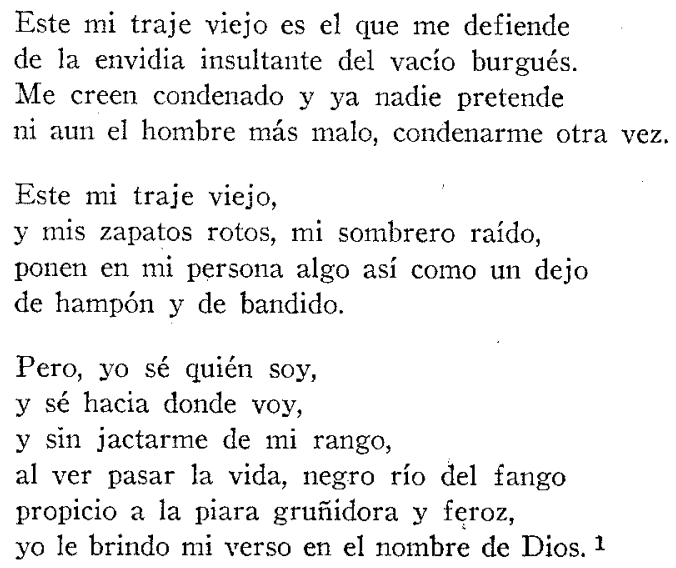

Sí, este mismo hombre que cada mañana viene a El Polo Norte a beber su tacita de café es terriblemente orgulloso. El sabe quién es y no se jacta de su calidàd de poeta, nos dice. La vida, para él, es un río de fango donde hoza la piara. Y la política de su país, un río revuelto donde medran los aventureros de la ambición de mando. Porque don Julio Correa tiene un agudo sentido cívico. Es el poeta de los desamparados y también el poeta de los rebeldes. Más de una vez ha convertido su lira en trompa guerrera y ha lanzado violentos $\mathrm{y}$ ásperos clamores revolucionarios.

Correa ha hecho sus primeras armas en las letras influido por los poetas del modernismo. Pertenece a una generación de escritores que admiró a Rubén Darío y profesó el esteticismo de Rodó. En el Paraguay, al amenguar el auge modernista, él fué de los primeros en reaccionar contra el passatismo literario. Mas no lo hizo como otros por motivos estéticos, esto es, porque el cambio operado en la sensibilidad de la época subsiguiente al rubendarismo postulara otras formas de creación. No. Correa reacciona por motivos políticos:

No cantéis más poetas vuestra vieja canción de los dulces amores y de la vieja pena, con las puerilidades de la dura cadena que un Cupido de palo os ató al corazón. 


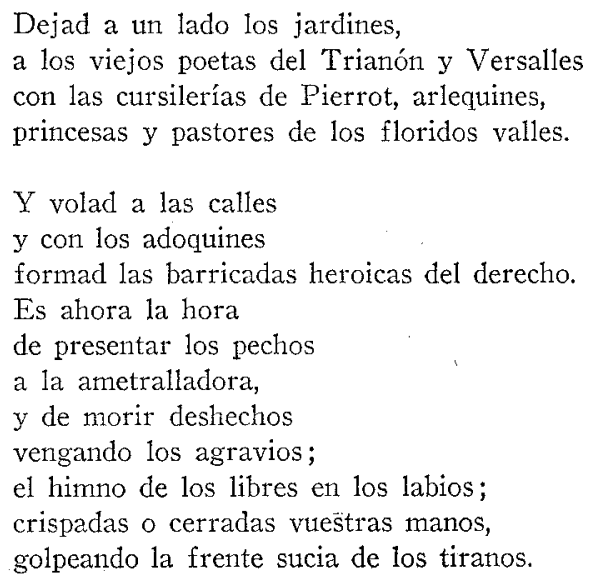

Mas volvamos al café donde vimos antes a don Julio Correa. Sentémonos a su mesa. Si os conoce, don Julio os trata con fina cortesía. Hay cierto embarazo en sus ademanes al comienzo de toda plática. Pero ahora ha sorbido la mitad de su tacita humeante y el momento es propicio para una plática confidencial. Le hablamos de sus versos; le decimos que estos nos gustan porque son fuertes, sencillos y sinceros. No aludimos a sus poemas revolucionarios. Nos referimos a sus pinturas líricas del suburbio, llenas de ternura, de emoción fina y delicada. Don Julio sontie tímidamente. Le halaga saber que es comprendido. Sus ojos azules se han vuelto más claros con la luz interna que los inunda; brillan sus pupilas como dos discos celestes en cuyo centro negrean las retinas.

“-Sé que usted no tiene el prurito del purismo. Más aún, nadie ignora que usted escribe en guaraní; que esta lengua es su instrumento literario favorito. Pero ¿̇ sabe usted? Su castellano me parece tan ... castizo. Sobre todo, en estos poemas.-." Y Y abrimos un volumen suyo que nos ha dedicado la víspera. "-En un escritor como don Manuel Gondra, o don Adolfo Aponte, el casticismo no es de extrañar. Ellos tienen ... bueno, la devoción de los clásicos. Pero en usted, por los temas que usted elige, tan paraguayos, tan guaraníes, diría yo...-" "-Yo no he leído a nadie, - contesta don Julio--, ni siquiera a los españoles. Yo no sé nada de nada. ¿Casticismo? Yo solamente he estudiado al pueblo. Antes, sí, leía el Quijote....." 
“-Y ¿ cuándo comenzó usted a escribir?-." Hemos ganado la confianza de don Julio. Nos aprecia porque... nos aprecia. Don Julio mira a todos lados. El café está lleno esta mañana: abogados, procuradores, políticos. A muchos de esos hombres que hablan y fuman en torno a las mesas vecinas acaso don Julio considere miembros conspicuos de la piara. Por eso, tal vez, se asegure de que nadie oiga la confidencia:

"-Y fué en el campo-, responde Correa. - Fué en Luque. Vicente Lamas, el poeta, era vecino mío. Y nos hicimos amigos. El fué mi maestro; él me enseñó a escribir. El me hacía leer cosas y corregía lo que yo escribía, al principio.-."

En Luque, pueblo a veinte kilómetros de Asunción, don Julio tiene una acogedora casa de campo: amplios corredores, grandes estancias con rústicos muebles y, aquí y allí, hamacas donde la siesta tropical se hace ritmo voluptuoso. En esa casa, construída en medio de un vasto patio poblado de árboles de sombra éspesa, don Julio, un día, se dió cuenta de que era poeta. Allí, en Luque, pueblo amodorrado, que vive días siempre iguales, monótonos, aburridos; pueblo de calles sin pavimentar, de roja tierra o verdísimo césped, don Julio halló sus primeros temas. Por ejemplo, el tema de la moza embrujada.

¿Cuando vió Correa a la moza a que el pueblo supersticioso acusa de embrujamiento? ¿La atisbó al pasar ella frente a la casa del poeta cuando éste descansaba tendido en la rítmica hamaca, o la columbró de lejos, un anochecer, cerca del cementerio? No lo sabemos. Acaso no exista en realidad la moza embrujada. Nunca se lo preguntamos. Pero la moza existe en el romance del poeta; vive en este romance:

La hija del sepulturero cuando por el pueblo pasa, las ancianas se persignan, las mozas la vista bajan.

Con unos ojos muy negros alumbra toda la cara, pero de amor no le dicen los hombres tha palabra, y su boca es golosina que nadie quiere gustarla.
En el baile poptular nadie le pide una danza. Dicen que bailar con ella trae a los mozos desgracia.

Yo no sé si será cierto, más dicen que está embrujada; con torvos sepultureros todas las tumbas profana, jugando un juego de amores que traerá una fea alimaña 
con las alas de vampiro y un ojo solo en la cara.

La hija del sepulturero piensa en silencio, cuitada, si el enterrar a los muertos será una cosa muy mala.
$Y$ ya loca de vergüenza, la cabellera desata y echa a correr por el campo lanzando unas carcajadas que machacan el paisaje y exprimen jugo de lágrimas.

Sencillo es este romance. Hay en él una atmósfera de conseja. La sencillez de los versos refleja la ingenuidad llena de superstición del pueblo del poeta. $Y$ hay una nota de piedad, de ternura, de profunda sinceridad. Correa se apiada de la moza embrujada como siempre se apiada cuando canta a los humildes.

$Y$ esta piedad sabe combinarse con ironía. La moza embrujada ha echado a correr por el campo. El eco de sus carcajadas se ha apagado en el paisaje. Mas nuestro poeta sigue atento a los rumores del pueblo:

Pasean las solteronas por las calles de mi barrio; van arrastrando el dolor vergonzante del fracaso de la castidad que el tiempo injusto, trocó en escarnio.

Silenciosas como sombras pasan con los ojos bajos, y cuando se hablan, esconden las palabras bajo el manto, $\mathrm{y}$ con temblor de hojas secas tiemblan sus pálidos labios

bajo el enrejado frío

que forman sus dedos magros.

$O$ van o vienen del templo;

y yo, al mirar sus rosarios, me finjo dos viboreznos que muerden sus pobres manos, que tal vez en el silencio de algún rincón apartado aún deshojen margaritas preguntando... preguntando...

Julio Correa ha publicado un solo libro de poesías: Cuerpo $y$ alma. $\mathrm{Y}$ en él se ha retratado de cuerpo y alma, con ruda y conmovedora sinceridad, desde el traje viejo que lo abriga hasta la más recóndita llamita de ternura que arde en su corazón. Es un cantor de sí mismo, un cantor del suburbio y un indignado cantor de iras revolucionarias. Las dos primeras formas de su canto aparecen en la primera y única edición original de su libro de versos. La tercera, en unas páginas de diferente papel y diferente tipografía. Estas páginas, numeradas del 87 al 94, agregó Correa posteriormente al libro. Por lo menos, al volumen por él dedicado al autor de este artículo. Vamos a examinar brevemente la obra de Correa en el primero de los aspectos indicados. 
Ya hemos visto cómo Correa nos habla de su traje viejo y su sombrero raído. Hay, sin duda, en los poetas un afán de retratarse. La imaginación y la sensibilidad de los poetas les hipertrofian el yo:

Ni un seductor Mañara, ni un Bradomín he sido

-ya conocéis mi torpe aliño indumentario ...2

nus dice Antonio Machado con modestia en su Retrato. Don Julio cree que lo creen condenado. $Y$ él cree ser un fracasado. Aun en momentos de dicha fugaz, no puede olvidar sus fracasos. Cuando a él viene la alegría, Correa quisiera esconderla para que no se la envidiasen y también quisiera :

... contar una a una las penas que he tenido, y hablar de mis fracasos y ponerme a llorar.

Y él calla su dicha "para no profanar el dolor sempiterno". Disimula la felicidad. Se cree señalado por doquiera de un cledo maligno y sabe que, al mirarlo, la gente dice:

... Ese pobre diablo,

parece que amanece el contento en su faz.

Y el torturado, impresionable espíritu de Correa, que pasa del más hondo abatimiento a la más vehemente exultación, responde a la malignidad ambiente:

... Sí, soy un pobre diablo y he dejado el infierno para no volver más!

Mas no se lo creamos: diez páginas adelante el pobre diablo ha caído de nuevo en profunda sima de depresión:

En anarga congoja el pasado desfila

mostrándome el fracaso que tuvo mi ambición.

$\mathrm{Y}$ aunque la vida en torno suyo se agite llena de encantos, no ya como un "negro río del fango propicio a la piara gruñidora y feroz", sino como una sirena de canto ubicto y tentador, el poeta no puede sobreponerse a su tristeza: 
En tanto que la vida para encantar me canta, un sollozo de angustias oprime mi garganta como un dogal de fuego y yo... no sé llorar.

Porque nuestro poeta, que es muy hombre, es también niño, y muy niño. En una nochebuena, asaltado por nostalgias de la infancia, piensa en su madre y en la evocación de su madre le domina la imagen de lo que es refugio y amparo: el tibio regazo. La nochebuena le devolvió en mágicas sugestiones la niñez pasada y le trajo

... un recuerdo también del acaso,

lleno de nostalgias de un tibio regazo,

y quedé llorando sin saber por qué.

En el romancillo La melancolía, Correa quiere recuperar el talismán que fué para él una vieja oración que la misma madre, cuyo tibio regazo añora, le enseñara en la infancia. $Y$ porque el poeta es hoy

$$
\begin{aligned}
& \text {... como una sombra } \\
& \text { marchando en la nada }
\end{aligned}
$$

le invade una inmensa melancolía al ver que los desencantos han marchitado la flor religiosa de la antigua plegaria que ahora

$$
\begin{aligned}
& \text { mecánicamente } \\
& \text { la dicen mis labios } \\
& \text { y no pasa nada } \\
& \text { en mi corazón. }
\end{aligned}
$$

Correa es pesimista. No dice cuáles fueron sus sueños ni cuáles sus fracasos. Nos habla de ellos de pasada y usa a menudo esta última palabra, fracaso, en poemas amargos. Siente odio y lástima hacia los hombres; odio a los malos, y lástima a los tristes. $Y$ a sí propio se tiene lástima. Lleno de piedad hacia la miseria de los desamparados, vierte en sus poemás su compasión por ellos. $\mathrm{Y}$ cuando la amargura y la desolación hacen presa de su propio espíritu, el poeta se apiada de sí mismo. $Y$ entonces dice que es un pobre diablo, uni niño que busca el tibio regazo materno, una sombra en la nada çue reza, mecánicamente, una oración cuyo encantamiento se ha desvanecido.

Cuando un poeta nos habla de sus sueños perdidos sin revelarnos cuál sea el contenido de ellos, bien podemos pensar que alude a los 
desencantos inevitables que la niñez, la adolescencia y la juventud experimentan al confrontar una concepción poética del mundo con la realidad ineluctable de las cosas. Esa confrontación la hacemos todos y todos sabemos cuán dura es la crisis espiritual concomitante. Ahora bien: en el caso particular de nuestro poeta, nos interesa indagar siquiera una de las causas de sus desilusiones ateniéndonos a las circunstancias concretas de su vida.

Hemos dicho que Julio Correa es, además de poeta, dramaturgo. Aunque no vamos a hablar de su teatro, no podemos menos de mencionar el hecho de que Correa es el fundador del teatro guaraní. Esta circunstancia le da una jerarquía única entre los escritores de su país. Pues bien: el gran sueño de nuestro poeta fué formar una troupe teatral. Y la formó y con ella salió a las tablas a interpretar sus propios dramas. $\mathrm{Y}$ esta troupe un día lo abandonó.

“-Don Julio, -le preguntamos una mañana en El Polo Norte: ¿qué significa su poema Cosas de títeres?-." E1 poeta apuró su tacita de café sosteniéndola en vilo con mano trémula por unos segundos. Luego habló con creciente emoción. El había querido interpretar el alma de su pueblo y por eso había escrito dramas en guaraní, el idioma que habla el pueblo. Para llevar su mensaje a las almas humildes buscó para intérpretes de sus ficciones teatrales un grupo de hombres y mujeres humildes. Y él les enseñó su arte:

Hizo el titiritero como veinte fantoches.

Dutante muchas noches,

frente al pobre retablo,

al Príncipe, a la Reina y al Arlequín y al Diablo, hechos de la madera encontrada al azar,

la humilde y buena gente aplaudió sin cesar.

Dijeron en la aldea

de los títeres: - Todos, buenos artistas son.

Y el titiritero, también con esa idea, sintió que le bailaba gozoso el corazón.

Fué a besar a sus títeres y se durmió tranquilo en una dulce calma, amarrados los hilos de los fantoches a su alma.

Mas Correa, el titiritero, -he aquí otra denominación en que combina orgullo y piedad hacia sí propio-, no tardó en despertar 
"de su sueño de paz". De este sueño lo arrancaron los títeres con gritos :

Nosotros somos hombres, sí señor...

señor titiritero: pase usted buenas noches.

$Y$ rompiendo los hilos se fueron los fantoches.

Desierto está el retablo.

E1 Príncipe, la Reina y el Arlequín y el Diablo;

el Rey con su corona

brillante de oro falso

y aquel Polichinela que con sus carantoñas hiciera reír tanto

se marcharon. Con llanto

clama el titiritero: - Es un cadalso

este retablo mío;

yo siento que te matan iay, corazón, de frío... :-

$Y$ entonces el titiritero reacciona $y$ maldice a sus fantoches poniendo en su naldición una fuerza pasional fulminadora. $Y$ tras el desahogo de su ira, siente Correa la tristeza, no exenta de amor dolorido, de su abandono, y al fin del poema reconviene a los ingratos:

Os hice de tarugos, puse en vosotros todos mis afanes prolijos, y fuisteis mis verdugos,

y hasta me abandonasteis ... lo mismo que unos hijos.

Esta fué una gran đesilusión para el dramaturgo guaraní. Sintió rabia, dolor y piedad. Piedad de padre abandonado que acaso espera ver regresar a los hijos pródigos. $Y$ piedad también hacia sí mismo. Aun el humilde pueblo cuya alma trató de interpretar en el tablado, le fastidia ahora. Ahora se llama a sí propio "loco Polichinela". Le duele que el aplauso "de la vulgaridad" le haya marcado. Se rebela el poeta contra el destino:

i. Oh, destino maldito, que me has hecho bufón!

Ya entre las bambalinas maese Ginés se crispa y me grita furioso: ¡Eh! payaso, más chispa, parece que te has vuelto de cartón.

$Y$ el poeta se disculpa. El, autor-actor, no puede fingir alegría en el tablado. Ya no tiene más "chispa": 
... el llanto de mis ojos ha mojado el yesquero y en vano lo golpeo contra mi corazón.

$\mathrm{Y}$ en el tambaleante tablado de la feria donde vende alegría con amor la miseria, por una ley infame, trágicamente absurda, divertiré a la pobre gente del arrabal, que ha de aplaudir ingenua la pirueta zurda $y$ el chascarrillo viejo que no tiene ya sal.

Cuando dijimos que Correa es un cantor de sí mismo, no quisimos decir que hubiera, como Walt Whitman, escrito un "Song of Myself". No nos dice el poeta paraguayo nada sernejante al "I celebrate myself, and I sing myself", pero si no se celebra a sí mismo poseído de una visión cósmica, interpretación consciente de la humanidad toda, Correa, modestamente, canta su dolor, su desencanto $y$, a veces, "una alegría inmensa". No obstante sus quejas, sus autorreconvenciones y su humildad al acusarse y apiadarse de sí mismo, el poeta reacciona al final de su libro y, afirmándose en una actitud varonil de estoicismo pesimista, decide resueltamente:

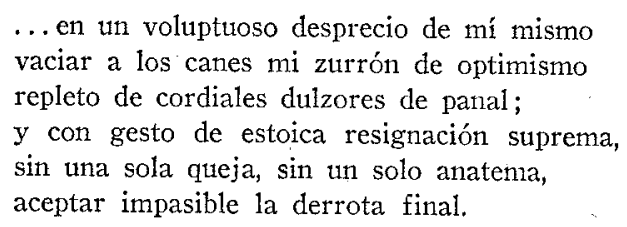

¿Pero se ha resignado don Julio Correa a su destino? ¿Ha renunciado a su arte, a la esperanza, a la poesía? ¿Quién sabe! Hace tiempo, mucho tiempo, que no escribe más versos ni dramas. Porque él, como muchos, ha estado viviendo el drama de su país: la anarquía sobreviniente a la guerra victoriosa con Bolivia. $Y$ nuestro poeta, como muchos, como todos, ha estado sufriendo, asfixiado espiritualmente en la atmósfera cargada de incertidumbre de una nación que no puede realizar la paz interna:

Es el dolor de todos la angustia cotidiana de vivir oprimidos...

A nuestro poeta le duele el Paraguay. Esta patria sufridora, de sin igual heroismo para defender su independencia, tiene más 
vocación para el sacrificio que para la felicidad. Sus hijos, divididos en partidos y facciones irreconciliables, no han aprendido aún a vivir juntos, a cooperar. Y por eso los poetas ya no cantan. Correa, sin embargo, no ha perdido toda esperanza. La angustia de su patria acaso no sea más que un gran dolor del parto de la libertad:

$Y$ es nada más que el gran dolor del parto, y ya está por nacer la libertad.

Esperanza tal vez de un hombre de partido que ve la salvación del país en el predominio del bando a que está afiliado. Pero esperanza, en fin. La paz interna parece ser un logro más difícil. Exige la cordura, la tolerancia de todos los partidos; la lucha leal de una oposición que sepa colaborar con el régimen a quien combata. $Y$ esta sabiduría política, que no es fácil de lograr en ninguna parte, parece más difícil en el Paraguay que en cualquier otro país.

Mas no nos olvidemos de nuestro poeta con consideraciones ajenas al propósito de este trabajo. Decíamos que, estoicamente, el poeta se ha resignado a la "derrota final". El estoicismo suele llevar a la inacción. ¿ Se contentará el alma de fuego de Julio Correa con una estéril pasividad? Tal vez no.

Una mañana vimos salir al poeta de El Polo Norte. El negro sombrero de anchas alas le protegía el rostro de los ardientes rayos del sol estival. Marchaba don Julio lentamente calle abajo, con el acostumbrado fajo de papeles bajo el brazo y una expresión dolorosa en la mirada.

"-Don Julio, ¿qué le pasa a usted? ¿No puede usted sobreponerse al ambiente, a lo que lo tiene tan anonadado y escribir, escribir, como una liberación, como una evasión para usted mismo? Hágalo por usted y hágalo por... el país. ¿Qué tiene usted? Diga. ¿Le ha hecho daño su prójimo?-"

Esta amistosa arenga o apóstrofe, o como quiera llamarse este arranque de cordial efusión, no fué importuno. E1 poeta escuchó con una viva llamarada en los ojos.

"-No, - dijo con energía. - Nadie me ha hecho daño. Yo mismo me he hecho daño. Yo tengo la culpa de todo. Yo me he llenado de veneno. Yo soy el malo.-." Y Correa siguió su camino, cl paso menos lento, por la calle llena de sol. 
¿Será esta autoacusación fecunđa? ¿Qué fermenta ahora en el espíritu del poeta? No lo sabemos todavía; pero la crisis que en él se está operando es posible que se resuelva en una nueva y generosa explosión de poesía.

Hugo Rodríguez Alcalá, State College of Washington.

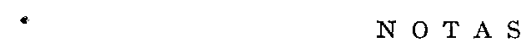

1 Sin otra indicación, todas las citas en este artículo se refieren a la obra, Cuerpo y alma, de Julio Correa, Buenos Aires, Editorial Difusam, 1943.

2 Antonio Machado, Obras, México (Séneca), 1940, pág. 128. 